\title{
Transforming distance education curricula through distributive leadership
}

\author{
Mike Keppell*, Carolyn O’Dwyer, Betsy Lyon and Merilyn Childs \\ The Flexible Learning Institute, Charles Sturt University, Albury, Australia
}

(Received 8 September 2010; final version received 30 September 2010)

\begin{abstract}
This paper examines a core leadership strategy for transforming learning and teaching in distance education through flexible and blended learning. It focuses on a project centred on distributive leadership that involves collaboration, shared purpose, responsibility and recognition of leadership irrespective of role or position within an organisation. Distributive leadership was a core principle in facilitating the transformation of learning and teaching through a Teaching Fellowship Scheme that empowered leaders across a regional distance education university. In parallel, a design-based research project analysed the perceptions of the Teaching Fellows in relation to blended learning, time/space, peer learning, innovation and equity issues in relation to distance education.
\end{abstract}

Keywords: flexible and blended learning; distributive leadership; design-based research; fellowships; transformative change; transformative learning

\section{Introduction}

Universities in the twenty-first century need to be responsive to the changing needs of societies by providing accessible and equitable learning and teaching options. Distance education universities, in particular, have traditionally been sensitive to the need to provide equitable options for their diverse range of students spanning the global multi-cultural educational community. To fulfil their mission effectively within this environment, a university needs to be continually evaluating, transforming and redesigning teaching and learning and undertaking curriculum renewal on a regular basis to ensure ongoing improvement of learning. In order to achieve these goals, traditional distance education universities are diversifying the range of teaching and learning options by utilising online teaching and learning and blended learning options in an attempt to be responsive to the changing needs of students, faculty and the organisational mission. Because "the centrepiece of any organization is the curriculum it offers its students" (Tierney 1999, 41), the design of curricula needs to be carefully considered to embrace the needs of students, and provide equitable teaching and learning options for the university community.

This paper outlines an institutional initiative to redesign courses (degree programmes) and subjects in relation to flexible and blended learning in an attempt to transform the curriculum so that it best meets the needs of higher education students. A Teaching Fellowship Scheme was conceptualised and implemented to focus on the

*Corresponding author. Email: mkeppell@csu.edu.au 
development (redesign of courses and subjects) by the academics involved in the Teaching Fellowship Scheme and individual development of the academics' knowledge and beliefs about teaching and learning. The transformative learning (Cranton 2006; King 2004) of the individual academics was examined through a series of semistructured interviews undertaken at the beginning of their project, mid-way through their project and at the conclusion of their project. In addition, the distributive leadership role of the academic in changing teaching and learning within their school was also examined to gain insight into the leadership role of the Teaching Fellow in relation to strategic change.

\section{Distributive leadership in relation to flexible and blended learning}

Distributive leadership focuses on collaboration, shared purpose, responsibility and recognition of leadership irrespective of role or position within an organisation. The term 'distributive leadership' has been circulating in educational discourse for some years, particularly in the context of primary and secondary education where it is often used interchangeably with 'distributed leadership' (Brown and Littrich 2008). In the schools context it is largely used to describe a broadly disseminated pattern of leadership operating throughout a school and school community, the organisation being led collaboratively by many participants rather than by a single authoritative being with the power of delegation. The central premise is that good leadership is foundational to good learning and teaching practice. In a university setting, 'distributive leadership' coheres with this horizontal model but also carries more layered connotations, focusing upon the 'collegial sharing of knowledge, practice and reflection'. Identified characteristics of distributive leadership include the building of trust, the creation of a learning culture and the sharing and dissemination of information (Brown and Littrich 2008). It is the contention of the authors that the sole use of hierarchical models of leadership is inappropriate in higher education to foster strategic change. New forms of leadership focused on principles of distributive may have potential in creating widespread strategic change. The architects of the Fellowship Scheme have been committed to a distributive leadership model, perceiving the scheme as a powerful conduit for the sharing of knowledge, skills and information within and between schools and an enabling strategy for the development of communities of practice across the university as a whole. It attempts to empower academic staff at all levels and fosters change across a discipline area. Within the Flexible Learning Institute, distributive leadership is a key component or style of leadership across all aspects of its work, with the Teaching Fellowship Scheme being the signature project of the Institute that focuses on capacity-building of academic staff and the redesign of subjects and courses using flexible and blended learning.

For the purposes of this paper, a caveat also needs to be entered here regarding the ambiguous - and sometimes interchangeable - usages of the terms 'blended' and 'flexible' in the context of learning and teaching. Blended learning utilises both physical and virtual environments and may be defined as "a design approach whereby both face-to-face and online learning are made better by the presence of each other" (Garrison and Vaughan 2008, 52). Garrison and Vaughan further identify it as a "fundamental redesign that transforms the structure of, and approach to, teaching and learning". Blended learning and teaching can occur at four levels of granularity: activity-level blending, subject-level blending, course-level blending and institutional-level blending (Graham 2006). A blended learning design may also be enabling, 
incremental or transformative. Enabling blends would address issues of access and equity to provide equitable opportunities in face-to-face, blended and fully online learning environments. Enhancing blends focus on incremental changes to the existing teaching and learning environment. Transformative blends focus on a major redesign of the teaching and learning environment (e.g. online problem-based learning).

Blended learning in higher education is becoming increasingly relevant to the tertiary sector and may be understood as the various course design elements that enable the ethical and educational principles of Flexible Learning and Teaching to be articulated. Dziuban, Hartman, and Moskal (2004) describe blended learning as a form of flexible learning - providing students with a means of learning flexibly in the way distance education has previously offered flexibility. Flexible learning offers flexibility in the time, pace and place of the study; and in the content, including, at times, flexible entry and exit and differing assessments. The flexible learning model emerged in part due to globalisation and its associated market forces, changing student demographics, the demand for increased and constantly changing employment knowledge, decreasing government and increasing private funding for universities, and improvements in communication technology and a shift towards different learning spaces - both physical and virtual.

\section{Transformational change}

In this development research (Reeves 2000) project, academics in the areas of education, environmental science, communication, computing and mathematics, commerce, philosophy and sociology participated in a Teaching Fellowship Scheme with the dual goals of transformational change of teaching and learning of courses/subjects using blended learning and transformative learning in relation to their beliefs about teaching and learning. The specific projects undertaken by the fellows related to the redesign of courses and subjects through blended learning and involved colleagues in each of their respective schools to assist in the process. It was essential that each fellow remained within their school for the fellowship as organisational transformation as an "organizational learning process extends incrementally across all levels of the organization, from the individual staff member to groups" (Roche 2001, 121). The development and research project attempted to maximise the positive impact of the teaching and learning initiative for the individual academic, school, faculty and university. Covey's (1989) principle of 'Think Win/Win' or principle of mutual benefit was a powerful concept in the conceptualisation, design and implementation of the Teaching Fellowship Scheme.

The ability to think at the systems level and examine all aspects of the initiative was essential. Effective strategic leaders in higher education must utilise 'whole of organisation' approaches and focus on “organization intervention that enables integration and linkage of people, ideals, priorities and goals as a means of achieving sustainable transformative change" (Roche 2001, 125). In addition, Roche (2001) also suggested that strategic leaders can only achieve these changes when they have a political power base in the university environment. In this instance the project was championed by senior management, supported by heads of schools and shepherded by a teaching and learning Institute. A number of other examples provide insight into the historical basis for the conceptualisation, design and implementation of this project.

Previous transformative change projects have demonstrated the need to work on sustained, immersive projects on strategically important areas to achieve organisational 
goals (Keppell 2002, 2007). Keppell (2002) described the transformation of a traditional medical curriculum and the organisational structure that was put in place to facilitate these changes. It discussed the management, design, development, evaluation, and training that was implemented in order to create web-based and computerfacilitated learning modules for the curriculum. The approach used systems thinking as a unifying framework for management, instructional design and training.

Systems thinking is a conceptual framework that examines the interrelationships between the often discrete aspects of management, design, development and evaluation of multimedia and online resources. Integral to this systems-based approach are aspects of building shared vision (goals, values and missions that are understood); accounting for mental models (deeply ingrained assumptions of how we understand the world); team learning (thinking together, achieving something that cannot be achieved alone); and personal mastery (continually learning and improving). (Keppell 2002, 69; Senge 1996)

In another implementation at the institutional level, Keppell (2007) examined the role of the instructional designer in transformational change in a Hong Kong context. It focused on the role of the instructional designer as a change agent in the university context through the process of brokering (Wenger 1998). By acting as brokers, instructional designers translate between different communities of practice - in a way similar to a language translator - and coordinate multi-disciplinary projects that foster connections across and within communities of practice. The instructional designer has a unique vantage point that may allow new possibilities for innovative design and professional development, and allow for the transformation of practice within the institution. Brokering is defined as "connections provided by people who can introduce elements of one practice into another" (Wenger 1998, 105). Five essential aspects are required of the instructional designer in the brokering process: translation; alignment between perspectives; recognition of legitimacy to influence the development of practice; reliance on the individual to have diverse identities; and suitability for certain individuals (Keppell 2007, 72-3). In this initiative, each of the Teaching Fellows implemented change using a number of these principles. The early stages of the work by the fellows appear to be achieving impact in enhancing communication across the school, providing in-depth discussion of the scholarship of teaching and learning and sensitising academic colleagues to innovative ideas that could be used in the teaching of the specific discipline. The research side of the project is examining how they are achieving these goals and how they are transforming their own learning throughout the process.

Parrish et al. (2008) evaluated the development of leadership capacity through the Leadership Capacity Development Framework (LCDF) for teaching and learning in higher education. Four Australian universities were involved in the project that involved mentoring of academic participants. The evaluation of the project suggested that successful aspects of the LCDF included: professional development activities; authentic learning activities; reflective practice; dialogue; and cultivating appropriate professional networks. In a similar way the Teaching Fellowship Scheme focused on professional development, reflective practice, dialogue and networking through authentic learning. It also attempted to create a community of practice to support the work undertaken by the Teaching Fellows. An important similarity between the leadership programme and the Teaching Fellowship Scheme is that they were undertaken for a sustained period of time to allow academics to transform their learning over time and provide exposure to a diverse range of activities. A major focus of the 
LCDF was the development of potential leaders across multiple levels of the university. The scholars in the LCDF suggested that broadening their understanding of what leadership can be and how it can be developed was a major benefit of the project. In a similar way, the Teaching Fellowship Scheme, by using principles of distributive leadership, is attempting to create champions who can initiate strategic change within their local school setting and through the redesign of subjects and courses using flexible and blended learning.

\section{Teaching Fellowship Scheme}

In 2008 a Teaching Fellowship Scheme funded through the office of the Deputy ViceChancellor (Academic) commenced at Charles Sturt University (CSU). The Fellows were seconded to work either with the Flexible Learning Institute (FLI) or the Education for Practice Institute (EFPI). This paper deals specifically with the FLI Teaching Fellows. The appointed Fellows have undertaken projects including curriculum/learning, programme review and development, course and subject redesign, development and evaluation of learning tools/strategies/management programmes, and scholarship in educational priority areas linked to the goals of the FLI and the EFPI. In 2008 (the first year of implementation) the Fellowships focused on blended learning and teaching, in conjunction with the use of CSU Interact (in-house name for the learning management system) and face-to-face teaching and learning.

The scheme was planned with broad intent, its purposes including but not limited to the following aims:

- The support and encouragement of the development of potential leaders across multiple levels and multiple areas of the university in line with the principles of distributive leadership.

- The facilitation of collaborative professional relationships between the FLI and the various schools and faculties and the strengthening of collaborative bonds between the schools themselves.

- The proactive development of course-relevant and subject-relevant blended learning systems at the university.

- The specific promotion and facilitation of CSU Interact as a pivotal teaching and learning hub.

The 2008 Fellowship projects were designed to build upon existing understandings of the transformative role of blended learning in ways that promote staff development and strategically improve the quality of teaching and learning in subjects and courses throughout the university. It is anticipated that there will be benefits to the Fellows in terms of career development given the enhanced opportunity for research output and for a discipline-specific investment in the scholarship of teaching and learning. It is further anticipated that there will be a natural accrual of benefit to each school and faculty and to the university overall. The original conception of the scheme envisaged the eventual participation of all 24 schools at the university through the targeted annual appointment of Teaching Fellows over a three-year to five-year period. Eight FLI Fellows from eight different schools were appointed to commence in July 2008. The 2008 Fellows concluded their appointments on 30 June 2009 and the next round of six Fellows began their appointments on or around 1 July 2009. In January 2010 a further eight fellows began their appointments and will 
conclude in December 2010. In 2011 a further six fellows have been funded and will commence in January 2011.

The Fellowship scheme provides a 50\% release from regular duties over a 12month period enabling academic staff to develop strategic learning and teaching projects. The decision to construct the time frame of the Fellowship programme in this way, rather than as a full-time release over six months, was carefully considered. Prior to the commencement of the scheme it was recognised that it would be impracticable and would place undue pressure on faculties and schools if outstanding teaching staff were entirely unavailable for the period of the fellowship. It was also felt that a continuing engagement in teaching throughout the period of the fellowship might provide an ongoing practicum where their investment in the scholarship of teaching and learning through their involvement in the scheme might draw upon and enhance their professional practice and their research project. At the highest level of functionality the Fellowship programme offers an opportunity for quality teaching staff to meld practice and research innovatively, providing distributive leadership within their own area of professional expertise and generating sanctioned change within the institutional boundaries of the university environment.

In practice the Teaching Fellowship Scheme adheres to the design principles for transformative learning. Transformative learning is defined as a process by which previously uncritically assimilated assumptions, beliefs, values and perspectives are questioned and thereby become more open, permeable and better justified (Cranton 2006, vi). The scheme is working to establish intersecting and collaborative communities of reflection and inquiry throughout the university, enabling the development of technological and pedagogical skills through distributive leadership.

The roles and perceptions of the Teaching Fellows are providing data for a research project focused on the transformative role of blended learning to improve teaching and learning in subjects and courses throughout CSU. In addition to interviews throughout the fellowship, individual interviews will be conducted with Teaching Fellows six months after the conclusion of their Fellowship term. The intent is to identify and record any changes or developments in the post-Fellowship period and to offer a further time and space for guided reflection. The scheme's approach to blended learning coheres with the core principles of social justice and ethical practice elucidated in CSU's 2007 University Strategy document. An institutional investment in the quality provision of flexible learning and teaching is foundationally underpinned by a commitment to access and equity across social, cultural, geographic (distance), generational and ability groupings. It is relevant to note here that some of the research projects of the individual fellows have drawn attention to specific issues relating to access and equity.

The research project focused particularly upon the transformative role of blended learning to improve teaching and learning in subjects and courses throughout CSU. Transformative change with regard to the Teaching Fellows and, for the purposes of the research project, is understood to be expressed in ways that include, but are not limited to, the following:

- An enhanced understanding of pedagogy and of their own pedagogical approach.

- An increased capacity and willingness to reflect upon their own practice.

- A willingness to think critically about received ideas and conventional approaches. 
- Readiness to innovate, to accept technological change and to build effective pedagogic connections between face-to-face and online teaching strategies.

- Renewed confidence with regard to leading and adopting change and innovation among their peers and within their own schools.

- Being empowered to negotiate perceived technological and institutional barriers to change.

- Preparedness to maximise the time/space opportunity of the Fellowship to actively engage in meaningful and relevant activities for their individual context.

To record these and other changes, the project utilised a development-based research process as outlined by Reeves (2000). The information provided by the Teaching Fellows in interviews and focus groups formed the basis for the research. The initial proposal for the Teaching Fellows Scheme identified it as a university wide strategic and transformative project that should promote innovation, transform educational practice in flexible learning and teaching, foster research based teaching and develop applied research outputs relevant to innovation in flexible learning and teaching.

The methodology adopts a multi-case study approach and applies several different strategies to examine the role of blended learning and the Fellows' own perceptions of blended learning. Input was also sought from the educational designers working with the Fellows. The strategies included:

- One pre-Fellowship audio-interview with each Fellow.

- One mid-Fellowship audio-interview with each Fellow.

- One post-Fellowship audio-interview with each Fellow.

- Two face-to-face meetings with Fellows and designers during the 12-month Fellowship (one at the beginning of the Fellowship term and one at its completion).

- Two teleconference focus groups with the Fellows.

- Analysis of incumbent Fellows reflective journals (bi-monthly reflective journals about the project).

- Analysis of information gathered in discussion during the 12-month Fellowship.

- Completion of a short final report (with guided questions) at the conclusion of the Fellowship term.

The Transformative Change research project will run for the duration of the Fellowship scheme over a three-year to five-year period. The feedback from the Teaching Fellows in the context of the transformative change indicators offers valuable insights into the direction the project is taking. All of these observations and individual interviews were recorded and transcribed throughout the Fellowship.

\section{Development-based research}

The rationale for choosing the research methodology of design-based research/ development research (the terms refer to very similar approaches and will be used interchangeably in this paper) is that it provides a methodology for progressing both pragmatic and theoretical aims of practice (Wang and Hannafin 2005). Development research (van den Akker 1999) aligns with the concept of 'use-inspired research' (Stokes 1997) that considers how our developments benefit the user, group or society 
and how our developments provide design principles for the academic community. Design-based research advances design, research and practice concurrently (Wang and Hannafin 2005). It has five characteristics, being: pragmatic; grounded; interactive, iterative, flexible; integrative; and contextual (Wang and Hannafin 2005). Wang and Hannafin define design-based research as:

A systematic but flexible methodology aimed to improve educational practices through iterative analysis, design, development, and implementation, based on collaboration among researchers and practitioners in real-world settings, and leading to contextuallysensitive design principles and theories. $(2005,7)$

Development research is defined as research "focused on the dual objectives of developing creative approaches to solving human teaching, learning, and performance problems while at the same time constructing a body of design principles that can guide future development efforts" (Reeves 2000, 25; see Figure 1). It is ideal in the context of the Teaching Fellowship Scheme that has parallel aims of developing innovative teaching and learning and the investigation of theory in relation to transformative change at an institutional level and transformative learning of the individual academics. The research intends to develop design principles suitable for the next iteration of the project and add to the body of literature on innovation in flexible and blended learning.

The research goals are interpretivist in nature and "focus on portraying how education works by describing and interpreting phenomena related to teaching, learning, performance, assessment, social interaction and innovation" (Reeves 2000, 23). A number of key principles will also be generated to foster further development in relation to flexible and blended learning within the university. These principles will guide future iterations of the project and are essentially development goals. The strength of this approach for investigating the Teaching Fellowship Scheme is that the researcher collaborates with the participants (Teaching Fellows) in the design and implementation of the project. The whole process will impact on the pragmatic and theoretical aims in relation to the practice.

Furthermore the Teaching Fellowship Scheme is using anthropologically driven design-based research. Bell suggests that:

anthropologically driven design-based research seeks to understand the nature of the introduced changes and their consequences from the perspective of the participants, and often it provides them with a voice and a source of influence on shaping changes to their settings. $(2004,245)$

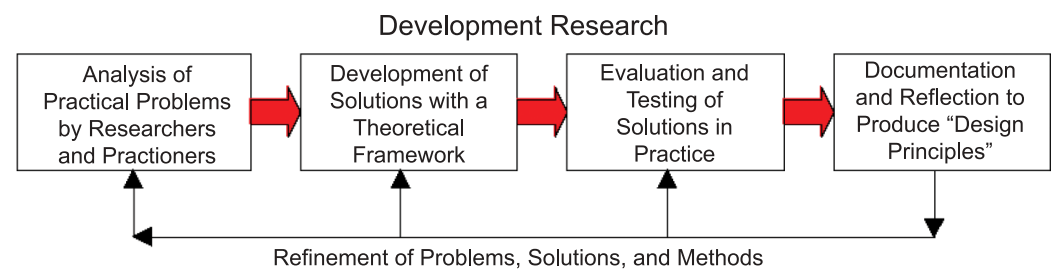

Figure 1. Development research process as outlined by Reeves (2000, 25). 
The Teaching Fellowship Scheme applies this principle of understanding how flexible and blended learning is introduced in the redesign of subjects and courses and the consequences of this introduction from the perspective of the Teaching Fellows. In this project, the Teaching Fellows are active agents in shaping the landscape of their discipline using flexible and blended learning. The project focuses on an intervention that will impact the:

localized nature of the practices and norms of the social groups investigated as they actually occur in their specific settings. Such a focus allows for detailed study of how new designs are appropriated, resisted, or even repurposed by groups that are assumed to already have significant cultural momentum before any intervention begins. (Bell 2004, 249)

\section{Teaching Fellows' perceptions}

As suggested previously, the research project focused on transformative change with regard to the Teaching Fellows. Six predominant themes emerged through the perceptions of the fellows. These themes are discussed in the following section.

\section{An enhanced understanding of pedagogy and of their own pedagogical approach}

With regard to the Teaching Fellows' understanding of pedagogy, especially with regard to blended learning, and of their own pedagogical approach, the following remarks were made at the conclusion of the 12-month programme:

So I guess the interesting amalgam of ideas around different modes of learning and ... different modes of learning as a part of students learning experience ... is ... a crucial aspect - that the notion of retaining or sustaining or maintaining student learning is pivotal to a conception of blended learning ... [This] has been where the real learning has come for me ...

This Teaching Fellow focuses on student learning whilst redesigning subjects using blended learning. They believed that the fellowship allowed them to understand the importance of this focus.

I started off with the perception that flexible learning was about a pile of different online technologies and I think I've increased my appreciation of blended learning or it's a lot more strategic than just having a pile of information out there, it's about ... the best course for information ... and the best way of delivering that teaching ...

This comment suggests that this Teaching Fellow has gained an understanding of design. They mention a strategic intent and the need to make a decision about how to optimise teaching and learning in a blended learning environment.

My understanding [of blended learning] has not changed, as when I first came into the program my perception was that it was a form of pedagogy, that it was a business strategy and it was a form of work organization. I think my experiences over the last twelve months have reaffirmed that. What I have gained is an understanding of how it is applied at CSU.

This is an insightful perspective of blended learning as too often we only focus on the teaching and learning benefits. With every new initiative we implement in the 
university environment, we need to be aware of the implications for the work practices for the academic as well the inherent benefits and disadvantages for the organisation and the workforce.

\section{An increased capacity and willingness to reflect upon their own practice}

The Teaching Fellows also commented on the ability to reflect upon their own practice:

.... you have the opportunity to think about things that you might not ordinarily have the time to do and you've got the space ... I'd say the biggest advantage is probably the potential to get a time break - to actually step back and think of the big picture, the forest.

The fellowship programme attempted to provide space for each fellow to examine how they could redesign their subjects or courses more effectively. Instead of layering further work on top of the current workload of the fellow, the fellowship programme provided a $50 \%$ buy-out of their current duties. This principle was essential for each fellow to reflect on their current work and examine innovative ways to progress their learning and teaching.

It was interesting to read around and to think ... about my own experiences during the fellowship ... about how people actually conceive of flexible learning and the relationship between issues of technology and the students' learning, and to see how that's something which people are grappling with in a really interesting and a robust way ... So I suppose that's been the really big substantive piece of personal learning that I have taken away. This fellow was able to see that learning must come first before the technology. Technology is simply an enabler of learning. Starting from scholarship of teaching ... I'm about to rediscover ... scholarship in teaching, pedagogy and curriculum. ... So the fellowship has just been terrific to make a space for that quality process to take time ...

Creating space for working on the fellowship allowed this fellow to network and rediscover pedagogy and curriculum. Busy academics with heavy teaching workloads often struggle to reflect on their teaching and learning.

\section{A willingness to think critically about received ideas and conventional approaches}

The readiness to innovate, to accept technological change and to build effective pedagogic connections between face-to-face and online teaching strategies is also increasingly in evidence.

I've got a new found respect for the work that the educational designers do, like having to engage us as academics with ideas or different ways of doing things and trying to get that on to other people's agendas.

This fellow has recognised the complex role of working across a disciplinary subculture as opposed to completing individual academic work. This fellow may be able to champion this perspective and assist in influencing positive change in teaching and learning.

The issues of flexible learning are fore-grounded in a way in which they haven't been in the past for many of the staff members who have been involved within the school and I 
think having that forum ... has been a useful vehicle to actually promote the ongoing conversations about the nature of our learning as well.

It is notable that there is a renewed confidence among some of the Teaching Fellows with regard to leading and adopting change and innovation among their peers and within their own schools.

And then there's peer learning and I think this has been the bigger aspect for me, that you know this fellowship has enabled me to work with my own peers a lot ... more than I had thought I would and that's been quite gratifying and illuminating ...

There was readiness to innovate, to accept technological change and to build effective pedagogic connections between face-to-face and online teaching strategies. In addition, there was also a renewed confidence with regard to leading and adopting change and innovation among their peers and within their own schools.

\section{Being empowered to negotiate perceived technological and institutional barriers to change}

Some of the Teaching Fellows became intermittently dispirited about difficulties in their path, but others clearly felt empowered to negotiate perceived technological and institutional barriers to change

... [When]there was a technical barrier ... I was able to talk to a lot to people about that particular technical barrier that I had to get over.

This need to solve a complex issue in the use of the technology provided a means for the fellow to influence the progress of learning and teaching through the learning management system. Another means of empowerment was the discussion that occurred in relation to teaching and learning:

... One colleague ... came in only this morning for about fifteen or twenty minutes - to ask about technology and techniques and also about the pedagogy underpinning the redesign of their subject. So that's an ongoing collegiality.

\section{Preparedness to maximise the time/space opportunity of the Fellowship to actively engage in meaningful and relevant activities for their individual context}

Most of the Teaching Fellows expressed a real determination to maximise the time/ space opportunity offered by the Fellowship to actively engage in meaningful and relevant activities for their individual (school/faculty/campus/cohort) context.

It [the Fellowship Programme] certainly does give a higher status to teaching within the institution which is traditionally the poor relative of research. I think the program in that sense puts it on more of an even par in terms of status and significantly in terms of resourcing.

This comment demonstrates the need to initiate projects in the university environment that clearly show the importance of teaching and learning. By allocating substantial resources to teaching and learning, university senior management send a clear message to the entire academic community that good teaching and learning is valued. 
... you're right; that ripple effect means that ... the more people who know what I've been doing ... means that I can talk to more people.

\section{Equity and access}

Equity for rural and remote students was a concern expressed by all of the Teaching Fellows consistently throughout interviews and discussions. One of the more valuable observations here addressed the fact that equality and equity are not necessarily the same thing - specifically that an equitable experience needs to be adjusted to circumstance and not to be rendered exactly the same.

I think the idea that we have to treat pupils in different cohorts equally might take us down some paths we don't really want to go. I'm going to suggest that what we should be concentrating on is equity and what is equitable is that we provide for our students the best possible education we can give them in their chosen mode of study - that's the equitable thing to do.

Nevertheless legitimate issues were raised regarding access to university systems and resources particularly for the most potentially compromised student groups (remote, indigenous, or those from lower socio-economic backgrounds).

There is concern that what we design simply will not be able to be accessed by our rural and remote students.

Throughout the project, the conceptual basis for the fellowship programme was continually refined by the feedback obtained through the interviews with the Teaching Fellows. At its core, the architects of the fellowship programme believe that by empowering individual academics to think deeply about learning and teaching, particularly in the area of flexible and blended learning, they will begin transforming their perspectives about learning and teaching. The use of professional development over the fellowship provided a focused approach in assisting academics to begin questioning their current beliefs about teaching and learning while being immersed in the redesign of their teaching.

\section{Conclusion}

The Teaching Fellowship Scheme utilising distributive leadership has transformed teaching and learning using flexible and blended learning. By focusing on redesigning subjects and courses, Fellows have engaged in innovative and relevant research to enhance their own professional development and pedagogical scholarship. By being involved in a community of practice focused on peer learning and building collaborative partnerships with academic colleagues, the Fellows have generated a number of outputs including presentations, publications and professional development in the scholarship of teaching and learning. Schools and faculties have also enhanced their understanding of blended learning through the Fellowship project. Teaching Fellows within their school have widened the awareness of flexible and blended learning strategies through discussion, presentations, informal and formal dialogue. Schools and faculties have also benefited from innovative options of teaching and learning using blended learning that should benefit student learning. The university has also benefited 
from the development of design principles that should guide future developments in the provision of innovative and sustainable practice in flexible learning and teaching through this project. The learning community at the university now has a range of learning options, which should assist in developing the university as a model of excellence in flexible learning and teaching in the global academic arena.

In this project, distributive leadership was utilised as a catalyst for curriculum change. It demonstrated how Teaching Fellows, through mentoring and sustained professional development, can instigate strategic change. By carefully managing the strategic process, the Teaching Fellows learned about the relevance of flexible and blended learning for the redesign of subjects and courses in a university context as well as leadership principles. A series of workshops and mentoring sessions provided a framework for empowering the fellows and assisting them to achieve their goals within their own school and discipline context. This approach has implications for professional development in higher education as the teaching fellows acted as distributed leaders implementing their own professional development with colleagues throughout their fellowship. The use of a contextualised, focused within-university sabbatical for academics provided a mechanism for changing beliefs about learning and teaching, infusing innovation into the redesign of subjects and courses, and instigated a change process about learning and teaching at the university level. Effectively this project has extended the reach of a learning and teaching institute in addressing its goals of strategic change throughout the university.

\section{References}

Bell, P. 2004. On the theoretical breadth of design-based research. Educational Psychologist 39, no. 4: 242-53.

Brown, Natalie, and John Littrich. 2008. Using a cross institutional collaborative model to deliver a national roundtable conference on assessment: A case study. Journal of University Teaching and Learning Practice 5: 8.

Covey, S. 1989. The seven habits of highly effective people. New York: Free Press.

Cranton, P. 2006. Understanding and promoting transformative learning: A guide for educators. 2nd ed. San Francisco: Jossey-Bass.

Dziuban, C.D., J.L. Hartman, and P.D. Moskal. 2004. Blended learning. EDUCAUSE Research Bulletin 7: 1-12.

Garrison, D.R., and N.D. Vaughan. 2008. Blended learning in higher education: Framework, principles, and guidelines. San Francisco: Jossey-Bass, John Wiley \& Sons.

Graham, C.R. 2006. Blended learning systems: Definition, current trends, and future directions. In The handbook of blended learning: Global perspectives, local designs, ed. C.J. Bonk and C.R. Graham, 3-21. San Francisco: Pfeiffer.

Keppell, M. 2002. Creating quality multimedia and online learning: Blending management, design, development, evaluation and training. In Eight contributions on quality and flexible learning, ed. H. Hansson, 69-89. Report 1:2002. Distum: Swedish Agency for Distance Education, Nybrogatan.

Keppell, M.J. 2007. Instructional designers on the borderline: Brokering across communities of practice. In Instructional design: Case studies in communities of practice, ed. M.J. Keppell, 68-90. New York: IGI Global, Hershey.

King, K.P. 2004. Both sides now: Examining transformative learning and professional development of educators. Innovative Higher Education 29, no. 2: 155-74.

Parrish, D., G. Lefoe, H. Smigel, and R. Albury. 2008. The development of leadership capacity in higher education. The Green Resource. Australian Learning and Teaching Council (ALTC).

Reeves T.C. 2000. Socially responsible educational technology research. Educational Technology 40, no. 6: 19-28. 
Roche, V. 2001. Professional development models and transformative change: A case study of indicators of effective practice in higher education. The International Journal for Academic Development 6, no. 2: 121-9.

Senge, P.M. 1996. The fifth discipline: The art and practice of the learning organization. London: Currency and Doubleday.

Stokes, D.E. 1997. Pasteur's quadrant: Basic science and technological innovation. Washington, DC: Brookings Institution Press.

Tierney, W.G. 1999. Building the responsive campus: Creating high performance colleges and universities. Thousand Oaks, CA: Sage.

van den Akker, J. 1999. Principles and methods of development research. In Design methodology and developmental research in education and training, ed. J. van den Akker, N. Nieveen, R.M. Branch, K.L. Gustafson, and T. Plomp, 1-14. Dordrecht, The Netherlands: Kluwer Academic.

Wang, F., and M.J. Hannafin. 2005. Design-based research and technology-enhanced learning environments. Educational Technology Research and Development 53, no. 4: 5-23.

Wenger, E. 1998. Communities of practice: Learning, meaning and identity. Cambridge: Cambridge University Press. 